\title{
Teaching Special Education during the COVID-19 Pandemic: An Exploratory Study
}

\author{
Leena Philip ${ }^{1}, \&$ Aasita Bali ${ }^{2}$ \\ ${ }^{1}$ Ph.D Research Scholar, Department of Media Studies, Christ University, India \\ ${ }^{2}$ Assistant Professor, Department of Media Studies, Christ University, India \\ Correspondence: Ms. Leena Philip, Faculty, Language \& Literature, Indus International School, India.
}

Received: December 21, 2021

Accepted: February 25, $2022 \quad$ Online Published: March 2, 2022

doi:10.5430/wjel.v12n1p246

URL: https://doi.org/10.5430/wjel.v12n1p246

\begin{abstract}
With the onset of the pandemic, there has been a massive shift and transformation in the way knowledge is disseminated. There has been a rise in distance/online learning, this includes teachers teaching remotely using various digitalplatforms. With almost two years of virtual learning, this has led to a demand for both teachers and students to upskill and equip themselves with technological capability. Effectiveness of e-learning has emerged to be an area of research, particularly in this context of the pandemic. This study explores the effectiveness of this alternate method of teaching on students with learning disabilities through the lens of parents and special tutors from renowned special schools in South Bangalore using interviews and focus group discussions. A pre-designed Likert scale questionnaire was also administered to 170 students with learning disabilities in South Bangalore to record the academic challenges they faced during their online classes. Results from the interactions with both parents and special tutors reveal there is a need to revisit learning and teaching strategies and improve access to new media educational technologies to help maximise uptake and success of the e-learning approach in the context of special education. Parents believe that the learner needs of children with disabilities during the remote learning scenario were not taken into consideration, special tutors shared their experience and limitations some which included difficulty in handling online classes, lack of financial support to invest in relevant technological platforms. The findings from this exploratory study highlight both the need for improving pedagogy in the remote learning contexts along with tutors requiring professional development workshops to conduct effective online classes that include incorporating various digital tools that meets the educational needs of children with learning disabilities. The study serves as an eye opener for special tutors, local education authorities and school administrators to revisit lesson plans, online teaching approaches, explore and invest in potential digital tools that could meet learner needs and improve the learning curve during the pandemic.
\end{abstract}

Keywords: e-learning, learning disabilities, online pedagogy, teaching strategies, special educational needs, pandemic, learning gaps

\section{Introduction}

Any learning must involve students being given the space to produce information across various disciplines and incorporate various perspectives. It is the role of educators to foster relevant skills in the process of learning, and most importantly impart skills such as critical thinking, problem solving, use of imagination, self-expression, and creativity (Duvall, 2020; Pink, 2006; Runco \& Pritzker, 2020; Sulaimani, \& Gut, 2019). Most online courses and distanceeducation strategies have been able to embrace technologies and adapt their pedagogical approach to build on these personal and professional competencies amongstudents thereby continuing to prepare them for the future (Cheng, 2006; Kaiper-Marquez, et al. 2020). However, in the context of special education, special tutors have resorted to the usual video conferencing applications to reach out to students and keep them engaged in the learning process (Kristóf, 2020). Li and Lalani (2020) suggests online learning have been shown to increase retention of information in general education, this includes language application that rely on virtual reality and artificial intelligence, virtual tutoring systems, video conferencing tools, or online learning software, there has been a significant surge in usage since COVID-19".

US educators from University of Chicago during the 1800's resorted to distance education model to disseminate content to correspondence program students who were at different places (Mclsaac, 1996). The World Wide Web transformed the whole 'distance education' approach which swiftly contributed to the emergence and growth of online 
teaching and learning. For instance, the Western Behaviour Sciences Institute offered its first fully fledged online course as early as 1981 (Harasim, 2000).

Online learning is an alternate method of teaching students partially or wholly through the internet (Guarnieri,2019). Students engage in learning and complete assessments over a virtual platform. This style of pedagogy has been an option for education institutions and large number of students often opt for this mode of learning (Roe, Blikstad, \& Dalland, 2021). However, in current times conducting classes online has become an urgent necessity because of the sudden outbreak of the COVID-19. The World Health Organization (WHO) had declared this situation a pandemic in early 2020 (Sohrabi, et al., 2020), and subsequently extended lockdowns were implemented across the world and have continued to the time of publishing this research. Most academic institutions were faced with challenges as teachers had to let go of their traditional face-to-face teaching models and shift to an online teaching/learning mode. This meant acquiring the knowledge or expertise to select the appropriate hardware and software and learning how to use it (Scott, 2018). Therefore, for many schools and other educational institutions, there has been a steep learning curve. Students across primary school and college have accessed education through e-learning tools and this includes children with special educational needs (Ameis, Lai, Mulsant, \& Szatmari, 2021).

On the other hand, online learning today, has shown to help students learn at their own pace, revisit concepts, and plan their own learning. While the effectiveness varies with age group, high levels of learner agency have been reported for both primary and higher education (Chaaban, Qadhi, \& Du, 2021; Mbati, 2020; Yates, Starkey, Egerton, \& Flueggen, 2020; Yan, Whitelock-Wainwright, Guan, Wen, Gašević, \& Chen, 2020).While online learning has emerged as an area of research particularly in the context of the pandemic, the impact or success of this learning mode for students with special educational needs have not been focussed on. Importantly, as FitzPatrick (2012) noted, the success or failure in any online learning is greatly dependent on the effectiveness of the medium and the student motivation. Further, to this, while $\mathrm{Li}$ and Lalani (2020) see promise in the emergent pedagogical approach they highlight how dependency on the internet and choice of learning system may have a negative impact on the learners' experience:

Boucenna et al.'s (2014) review showed many opportunities were available to support learning through use of technology, but further research was recommended. Similarly, more recent research has advocated for additional studies in the context of special education and assistive technologies (Yarn et al., 2020; Yates et al., 2020). Thus, with the new demand for an online pedagogy, it is even more crucial to explore the impact of existing technologies on students' learning experiences in this context. The ability to customise learning to address learning gaps and meet learners' needs in the online learning environment during such unprecedented times depends on tutors. Yan et al.'s (2020, p. 2053) study of children K-12 recognised the role of smart phones in their provision of substantial advice for teaching in general, concluding: educational authorities and schools should provide sufficient technical support to help students to overcome potential internet and technical problems, as well as choosing online learning platforms that have been customised for smartphones. Second, customising the online pedagogy design for students in different school years focusing on providing sufficient guidance and differentiation for young children, creating online collaborative opportunities for middle school children and adolescent, along with offering additional learning resources.

Children with special needs typically have trouble with learning and physical activities They tend to have other behavioural, emotional and communication problems that impair learning (Stake \& Hornby, 2020; Misciagna, 2020). These children are placed in schools that offer special educational needs (SEN) by licensed specialised tutors and therapists (Bryant, 2017), since they require assistance and adjustments in their personal and academic life. The social learning theory by Bandura (2012) highlights the importance of the learning environment being able to foster students' engagement with the people around them in their learning environment.

As Miller (2011, p. 236) aptly stated, "The main characteristic of the social learning theory, are the centrality of observational learning, a causal model that involves an environment- person- behavior system, cognitive contributions, and self-efficacy and agency" (cited in Lamport, Graves, \& Ward, Miller, 2012, p. 56). Thus, providing the necessary attention within given time constraints can make it challenging for special tutors to meet demands and ensure inclusion of pedagogical practices. The pedagogical approach should aim at improving their physical, emotional, social, and intellectual capabilities in the online learning environment which is a challenging area. Taking these factors into consideration, the study sought to understand in what ways has online learning created an impact on children with special needs.

While some believe that the unplanned and rapid move to online learning - with no training, insufficient bandwidth, and little preparation - will result in a poor user experience that is unconducive to sustained growth, others believe 
that a new hybrid model of education will emerge, with significant improvements and benefits.

\section{Review of Literature}

To address social, communication, behavioural, and adaptive skills in those with special educational needs (SEN), effective technology-based programs have gradually gained recognition among both practitioners and researchers. With the uptake of digital communication technologies, students with SEN have been found to have a special interest in computerised learning, which can motivate learners to access new knowledge. There are several reasons for this, researchers have identified certain advantages, which include the support of technology for provision of both consistency in clearly defining a task and directing the specific focus of attention thus reducing distractions from unnecessary sensory stimuli, which can include interactions with peers (Lofts, 2018).

Social situations are often challenging and confusing for those with learning disabilities, thus attending to a computer or other screen technologies (e.g., Smartphone; iPad) can free the student from disruptive social demands. According to Stiller and Mößle (2018), students use screen media as much as their peers, thus making this an inclusive option. Moreover, unlike the customary classroom social environment, online learning experiences educational technologies can be integrated to help address these learners needs. Technology also includes the use of robotics, interactive video/DVD, hand-held and touch pad devices, internet-based, collaborative, virtual environments, eye tracker-based gaze-contingent visual displays, and shared active surfaces that help children with learning disabilities (Daud, Maria, Shahbodin, \& Ahmad, 2018; Salemi, Reis, Saifhashemi, \& Nikgohar).

To encourage social, functional, and behavioural skills in individuals with ASD, specific technologies, such as authoring software tools, video and self-modelling, speech-generating devices, and virtual reality have been incorporated as intervention strategies. Several skills to help students prepare and adapt in various social settings have been instilled in students using such innovative technology-based interventions. These innovations have shown positive results in fostering student agency in their learning, for example, allowing students choice and the ability to initiate, maintain and end activities. They support students' daily functional needs, including facial recognition and ability to read non-verbal cues. In addition, they also support students' safety skills, vocabulary development, and reading skills and as necessary their speech. In turn, this can facilitate students' confidence and participation in class discussions enabling them to learn better (Anoyiannakis, 2013; Kumm, Viljoen, \& de Vries, 2021).

Recent studies tend to emphasize the potential of technology more than its demonstrated effectiveness. (Gillian Hayes, Patrice Lynne Weiss, Gregory Abowd, 2007). Technology is said to have the power to enable students to adapt to different learning environments. Rather than the monotonous classroom teaching, which is mostly teacher centric, students find it easier to discuss, engage and pay attention in technology integrated classrooms as they engage with multimedia driven content. Students with learning disabilities are visual thinkers, and technology can help them access information in a graphic and simplistic manner. This includes responding to various sounds, which enables student responsiveness because they may react differently to different sounds (Lofland, 2018).

Given the fact that computer-based technology uses the multimodal principle of functioning which integrates videos, pictures, graphic, animation, and sound, there is no doubt about the fact that computer or technology-based teaching keeps students with learning disabilities engaged. Studies has shown that computer-based technology can have a positive impact on students with learning disabilities. This is reflected in Dikusar's (2018) study that used the following five technologies: tactile and auditory prompting devices, video-based instruction and feedback, computer aided instruction, virtual reality, and robotics. Learners were able to learn better when technology appeals to their senses. Learning through touch and feel stimulates senses and help children comprehend and retain information better. Researchers have also discovered there is a need to make technologies flexible for people with special needs and in keeping with Kumm, Viljoen, and de Vries, (2021) "these technologies need to be designed from the outset not only with the end-user, purpose, domain and setting in mind, but also with the accessibility, affordability, acceptability and scalability in the specific context and community of the end-user in mind".

Mobile technologies are used by tutors along with provisional assistive and adaptive learning technologies. The touch screen of the first prototype, 'Mocoto', had the capabilities to allow for easy interactions with a comprehensive library of cards that were preinstalled. This software was flexibleenough for content to be added along with audio and video clips as well as images that special tutors /users might create. Such a strategy allows the creation of a more personalised database where images can be easily managed and sorted for ongoing application to learning needs.

Similarly, for children with Autism and limited speech, iPads have been successfully used as speech-generating devices (SGDs) (Parsons, Cordier, Lee, Falkmer, \& Vaz, 2019). They have been used to support the development of basic literacy skills such as picture/word matching where students are easily able to signal their answer (de Lima 
Antão et al., 2020; van der Meer et al., 2014; Westerveld, Paynter, Trembath, Webster, Hodge, \& Roberts, 2017). This approach was seen by Van Der Meer et al. (2014) as being relevant in relation to developing and supporting other academic/literacy skills for ASD students with speech difficulties and improving problem-solving skills.

Online learning has also incorporated the use of emerging technologies like virtual reality to enable students to visualise the learning process and engage and interact with information and multimedia to support understanding and stimulate learning. The visualization process refers to visual representation in computers, auditory components or any other forms of sensory outputs displayed in a virtual world (Wedyan, Al-Jumally, \& Dorgham, 2020). Virtual reality as a tool can assist the students' learning while at the same time alleviate many of the typical issues associated with the traditional approach to teaching and learning. However, Standen and Brown (2006) note that there are limitations of its applicability to students with extremely limited visual ability, but their situation can be enhanced through developing acoustic virtual environments. Students' motivation and agency in their learning can also be enhanced using video games. Hiniker, Daniels, and Williamson (2013) point out their therapeutic qualities particularly for children with autism. Thus, it appears virtual media technologies can help children with special educational needs in wide range of ways such as gaining an overall understanding of their environment, and learning and practising vital skills like attention skills, expressive communication skills, organisational skills, academic skills, and self-help skills, which all support functionality and learning independence (Mohammad \& Abu-Amara, 2019). This is reinforced by the work of Boser, Goodwin, and Wayland (2014) who established that new media technology can be used not only as a source for entertainment but also as a tool for education and development of social skills to increase learning autonomy among students with learning disabilities (Lamport et al., 2012). In this way the use of digital communication technologies and Web 2.0 can help foster the transition from traditional information transmission views of learning to a more interactive social constructivist model thus helping to create a more participatory educational environment.

As Cochrane (2016) specifies: "it is the potential for mobile learning to bridge pedagogically designed learning contexts, facilitate learner-generated contexts, and content (both personal and collaborative), while providing personalisation and ubiquitous social connectedness, that sets it apart from more traditional learning environments".

From the perspective of families of children with disabilities the potential of current technological solutions to support the challenges they face daily provides much hope. Many families across the world need individually adapted practical support as well as financial support (Kumm et al., 2021). They especially need support that takes into consideration the situation of the whole family as a group. Researchindicates that siblings of children who are autistic tend to take on more responsibility for the family's wellbeing and may exhibit more maturity than other children of their age group (Anderson, Liang, \& Lord, 2014; Ferraioli \& Harris, 2009). However, research into siblings of ASD and Downs Syndrome (DS) children suggests that in adulthood their outlook for the future may be somewhat pessimistic depending on several factors. They were generally more positive when their sibling with special needs had higher levels of functional independence, and they had acquired problem-focused coping strategies, and had relatively easy access e.g., lived in proximity and had regular contact (Orsmond \& Seltzer, 2007). Of note is the growing availability of support to families using technology (McIntyre, 2019). This can support communication, learning and management strategies and facilitate children's social life, thus improving the family's social life at the same time (Hastie \& Stephens, 2019). As Ameis, et al. (2021) show, technology was vital in supporting evidence-based interventions to address the challenge of COVID-19.

Thus, this literature review shows that current research tends to be focused on how technology can facilitate children's ability to learn and to manage in school. It highlights the growth and success in the use of applications that are supported through screen and mobile technologies besides computers, such as iPads and Smartphones (Stakes, 2020). While these tools are also applicable to mainstream pedagogical needs the research shows additional technologies are in train that are relevant to the specific needs of students with disabilities, including those on the Spectrum - ASD and ADHD, those with specific learning disabilities, and those with visual and hearing impairment. Munoz et al. (2019, p. 7955) concluded:

technology has improved the lives of many people with disabilities. This is because it helps them to compensate for various verbal and interaction problems, as well as facilitating exchanges between people with ASD, family members, experts, and others. Thus, this compensation and facilitation expands new forms of communication, socialization, learning, and employment options.

There is a lack of long-term studies on the feasibility of technology specially in the context of special education and the pandemic. Studies don't include the perspective of families of children with special need and how the technology impacts the interactions within in the family including acquisition and consumption of knowledge. 


\section{Research gaps}

Analysis of these studies indicate that there is a growing concern to incorporate technology to support students with special education needs both in class settings and in the home and out of school environment. However, further research on student motivation and parent willingness to assist in the learning process using technology is essential. This particularly applies in the context of special online education particularly during the COVID-19 pandemic as parental support is required to help with the e-learning process. Thus, the present research set out to explore the psycho-social stressor faced by students with special needs, parents, and special tutors, setting the following objectives to:

1. Understand the pedagogical and instructional design adopted by special tutors in the context of remote learning

2. Assess to what extent learners with learning disabilities take an active role in their own learning and skill enhancement

3. Identify challenges faced by the learners with learning disabilities in an online setting.

\section{Research Methods}

\subsection{Sampling Procedures}

Convenience sampling technique was incorporated for this study as it required teachers and parents to share challenges in the context of remote learning. This technique enabled the researcher to obtain relevant information from groups that were easy to reach out. The sample size taken for the study include 10 parents and 7 special tutors from 3 leading special education schools exclusively teaching children with special needs in Bangalore -South. Overall, there are 5 special schools located in the South of Bangalore (Bangalore education, 2020) that predominantly cater to children with learning disabilities, physical disabilities, and Intellectual Disabilities. Using the same sampling technique, 170 students between grades 8-10 from 3 renowned schools in South Bangalore teaching students with learning disabilities (Dyslexia, Auditory processing Disorder and Dysgraphia) were approached to fill a simplified questionnaire that tests their learning satisfaction level.

\subsection{Research Tools}

This study followed an exploratory approach to gain background information that helps to understand the problem, explore the research questions, and have a better understanding of the research problem (Creswell, 2014). Qualitative method used in the study were interviews that captured the overall experiences and challenges teachers and parents faced in the online learning environment. For the current study, the researcher studied the impact of E learning among children with learning disabilities like Dyslexia, Auditory processing Disorder and Dysgraphia. Meanwhile, snowballing technique was used to reach out to other parents of students studying across these schools located in south Bangalore. Questionnaires and Interviews were used as means to gather information.

Additionally, a pre-designed questionnaire was created to assess the academic satisfaction levels of students with special educational need. The questionnaire was simple and administered to 170 students with learning disabilities across 16 special schools in India. The questionnaire contained 10 simple questions with a five-point Likert response scale making it easy for respondents comprehend and respond. The items in the questionnaire were selected based on the review of the literature, along with inputs from expert special tutors with over 8 years of teaching experience (Johnson, 2008).

The research was also conducted to understand the way special tutors and children with learning disabilities engage and learn in the online distance learning mode. It also intended to understand if online classes were designed to help the students with their skill development. Parents of students between the grades 9 and 10, higher grades, where contacted for the study. Parents and tutors volunteered in response to the researcher's invitation. Consent to participate in the study was sought using a consent form. Data for the research was gathered through semistructured interviews using WebEx ${ }^{1}$, a video conferencing application. Each interview lasted up to at least 40 minutes. Since the participants had reservation about recording their interview data because the discussion required them to point challenges they faced, which included the instructional design, gaps and expectations from the institution, all information emerging from the discussion was noted down by two moderators to avoid missing any crucial information.

\footnotetext{
${ }^{1}$ https://www.webex.com/ 
All participants were informed of the purpose of the study, and that data would be processed,analysed, and published. They were assured of their anonymity in any reporting. Data derived from the interviews were analysed using the classical content analysis and Key Word in Context Method (KWIC).

\subsection{Theoretical Framework}

Social learning theory (Bandura, 2001) build to the theoretical framework for the study because, as noted earlier, it is particularly relevant to special education in underpinning the pedagogical approach to addressing the challenges of supporting students' engagement with the people and the learning process. One of the ways these children learn is by mimicking what they see around. They observe and interact with their environment, people in the families, special tutors, peers, and act on what has been exhibited. In this style of learning, actions are rewarded or not thereby making observation and motivation as the key factors that influence learning behaviour.

\section{Data Analysis and Discussion}

4.1 Assessing Student Perception and Satisfaction of Their Learning Environment, the Responses from the Survey Were Analysed to Extract Percentages Of Participants Answer For Each Question

Table 1. Responses to the survey question

\begin{tabular}{|c|c|c|c|c|c|}
\hline Question & $\begin{array}{l}\text { Very } \\
\text { Dissatisfied }\end{array}$ & Dissatisfied & $\begin{array}{l}\text { Neither Satisfied } \\
\text { nor Dissatisfied }\end{array}$ & Satisfied & $\begin{array}{l}\text { Very } \\
\text { Satisfied }\end{array}$ \\
\hline $\begin{array}{l}\text { How was your experience with the online classes } \\
\text { this year? } *\end{array}$ & $16.4 \%$ & $70 \%$ & $12.7 \%$ & & \\
\hline $\begin{array}{l}\text { How satisfied are you with content taught this year? } \\
*\end{array}$ & $12 \%$ & $74 \%$ & $12 \%$ & & \\
\hline $\begin{array}{l}\text { How pleased are you with the format of the course } \\
\text { designed during the lockdown? (Definition of } \\
\text { "format" behind the questionnaire) }\end{array}$ & $21 \%$ & $58 \%$ & $20 \%$ & & \\
\hline $\begin{array}{l}\text { How was your experience with navigating through } \\
\text { the resources shared by your tutor this year? }\end{array}$ & $18 \%$ & $54 \%$ & $27 \%$ & & \\
\hline $\begin{array}{l}\text { How satisfied were you with the help you received } \\
\text { from your teacher in this academic year? } *\end{array}$ & $12 \%$ & $52 \%$ & $32 \%$ & $1.8 \%$ & \\
\hline $\begin{array}{l}\text { How fulfilled or disappointed were you with the } \\
\text { online communication you had along with your } \\
\text { instructor?* }\end{array}$ & $14 \%$ & $34 \%$ & $47 \%$ & $3.6 \%$ & \\
\hline $\begin{array}{l}\text { Were you fulfilled with the interaction and } \\
\text { collaboration you had together with your } \\
\text { friends/classmates in lesson this year? * }\end{array}$ & $7.3 \%$ & $50.9 \%$ & $40 \%$ & $1.8 \%$ & \\
\hline $\begin{array}{l}\text { Are you satisfied with the feedback you have } \\
\text { received from your instructor this academic year? } *\end{array}$ & $33 \%$ & $47 \%$ & $13 \%$ & $4 \%$ & \\
\hline $\begin{array}{l}\text { Have you been satisfied with the } 1-1 \text { sessions with } \\
\text { your instructors? }\end{array}$ & $54.5 \%$ & $45.5 \%$ & & & \\
\hline $\begin{array}{l}\text { How satisfied have you been with the group/ } \\
\text { individual activities undertaken in class? }\end{array}$ & $21 \%$ & $20 \%$ & $58 \%$ & & \\
\hline
\end{tabular}

Most questions were designed to capture their satisfaction level with the online curriculum, content, and student-teacher engagement. Based on the data derived from the sample, it was evident that students were not satisfied with the learning platform and the pedagogical designs adopted by the tutors during the pandemic. The usual offline classes offer 1-1 face to face interaction to build rapport and make student acclimatized to social settings. However, in this case the results indicate no effective 1-1- sessions held to provide feedback or any form of counselling to students resulting in a lack of motivation and desire to learn. Furthermore, majority of the respondents were dissatisfied with the number of online interactions and collaborations they had with their friends/classmates in class this year. This indicates the online environment taking a toll not only on their academics, but most important on their communication and social skills. Students with special needs require content that is customized according to their learning needs, the lessons must be differentiated for each student in class, however with the online learning $58 \%$ of the students showed their dissatisfaction with the format of the course and have not been able to navigate through the resources and digital learning materials shared with them.

The data derived from the questionnaire were further developed and integrated in the semi-structed interviews with teachers to explore the factors affecting learning and teaching in the context of special education.

\subsection{Understanding the Challenges Faced by Special Tutors in the Online Teaching Mode and Exploring Parent's Attitudes Towards Their Children's Online Learning.}

Tables 2 show three key terms that were frequently listed during the interview with the parents of children with Published by Sciedu Press 
learning disabilities The words emerged from the content analysis of the data. These terms are closely related with the parents as they express the challenges reported in relation to the remote learning process. The frequency count for the number of times is also displayed.

Table 2. Terms used by parents in semi structured interview

\begin{tabular}{|l|l|}
\hline Term & Frequency \\
\hline Distraction & 31 \\
\hline Isolated & 20 \\
\hline Collaboration & 19 \\
\hline Engagement & 18 \\
\hline Knowledge & 16 \\
\hline Skills & 16 \\
\hline Content delivery & 15 \\
\hline Focus & 13 \\
\hline Lack of 1-1 attention & 12 \\
\hline New teaching strategies & 8 \\
\hline Failure & 7 \\
\hline Faculty support & 6 \\
\hline Sensory Overload & 6 \\
\hline Lack of knowledge & 1 \\
\hline Time management & 1 \\
\hline Multitasking & 1 \\
\hline
\end{tabular}

Table 2 sheds light on the reasons why parents found online classes challenging for their children. The following points summarize the findings from the focus group discussion:

1.Students with learning disabilities face irritability due to sensory and information overload.

2.Lack of focus in class, distancing from class.

3.Students keeping their camera off and not responding to tutors/peers resulting in students shutting away from classes.

4.Lack of response/engagement/collaboration in the current learning format.

5.No opportunities for classroom activities due to sensory overload; students are unable to socialize and communicate amongst their peers or with the special tutor.

6.Students with learning disabilities falling back on skills as tutors are focusing on academic content and syllabus completion.

7.With the lack of activities, engagement, students are further isolated

8.Parental concern about monitoring long term exposure to technology and digital screen.

9. Parents unable to make time to help their children in their academics. This includes lack of knowledge about teaching strategies and approaches for children with learning disabilities.

Table 3. Terms Used by Special Tutors in the Focus Group Discussion

\begin{tabular}{|c|c|}
\hline Term & Frequency \\
\hline Lesson Plan & 34 \\
\hline Technology & 29 \\
\hline Funding & 16 \\
\hline Professional development & 22 \\
\hline Parental Support & 20 \\
\hline School Administration & 18 \\
\hline Syllabus Completion & 21 \\
\hline
\end{tabular}




\begin{tabular}{|l|l|}
\hline Exam readiness & 17 \\
\hline Students unresponsive & 31 \\
\hline Lack of 1-1 attention & 16 \\
\hline Camera & 13 \\
\hline Teaching strategies & 18 \\
\hline Sensory Overload & 13 \\
\hline Parental Pressure & 12 \\
\hline Adapt & 14 \\
\hline
\end{tabular}

Table 3 illustrates the terms derived using the KWIC technique, it symbolizes the special tutors' attitudes towards online learning and how it is commonly seen as a concern by many tutors teaching students with learning disabilities online during the pandemic. The following points summarize the findings from the focus group discussion:

1. Special tutors not able to reach out, establish rapport and connect with students in the online learning platform

2. Lack of response and readiness towards from students end as current classes appear to be heavily teacher centric. Special tutors sharing information, instructions, attempting to get students to engage which leads to sensory overload.

3. The pandemic has forced schools to cut down the fees as a result affecting the funds to invest in relevant technologies.

4. Lack of funding for assistive technologies that could be used by tutor alongside teaching, balancing sensory overload.

5. Special tutors lack knowledge of emerging technologies that could be integrated in class.

6. Several tutors are faced with the problem of digital divide and are trying to adapt to distance learning mode and understand how to use technology effectively.

7. Pressure from school authorities to submit lesson plan's, complete portions in time, prepare students for exams, in time as a result there is no focus on skill enhancement, particularly social and communication skills.

8. No access to workshops for faculties to build agency and increase knowledge of digital teaching strategies that could be incorporated in the distance mode to enhance learning.

9. Special tutors are faced with pressure from school administration to complete portions ahead of time, continue with the existing technological platforms while they try to address parental concerns about the issues in online learning.

\section{Discussion}

From the above data, it is evident that there have been several challenges faced by parents, students, and special tutors in the context of online learning during the pandemic. Special tutors require professional development training to adapt and learn to utilize emerging educational technologies. The conventional mediums used to teach students currently involve Microsoft Teams and WebEx. Zoom was ruled out by most tutors due to issues concerned with privacy and hacking. School administrators are faced with challenges to organise specific teaching training programs for the special educational needs department due to lack of funds and digital experts in the subject area. Currently most lesson plans are created with an intent to cover syllabus as a result there is merely delivery of academic content in class. These classes lack any activities or learning experiences that promoted skills to enhance the use of the technology as students appear unresponsive. Opportunities created for socialization and communicative interactions did not go well and the outcome was not achieved.

Most students with special needs often learn through observation and modelling (Thomas,2022), however this could not be executed in the online setting particularly when students were disconnected and did not engage in class. This was because learning online was found to cause an overload of information resulting in students 'shutting off' from the class by turning their cameras off. Thus, with lack of support, response, access to resources and technical knowledge, special tutors were forced to teach students with teach students with learning outcomes unmeasured or assessed. This equated to a pedagogical style more in keeping with delivering lectures and the addition of presentations to complete the syllabus requirements.

The various challenges that emerged were raised by both special tutors and parents and the concern for students' difficulties with learning online was also reinforced by their concern for their progress. Lack of progress was 
attributed to students' low involvement, special tutors lack of technical knowledge to make learning online more interesting and lack of further technical support from school authorities. Before COVID-19, special tutors reported that they often created content using a variety of formats, thereby making lessons lively as it attracted students' attention and increased their retention of information. This was seen as a strength of their pedagogical approach that they were unable to duplicate for students with special needs.

Moreover, parents found it extremely challenging to dedicate extra time to their children due to the rise in their workloads and generally making ends meet in their home situation during the pandemic. One of the main challenges appeared to be feeling helpless because they lacked the knowledge to support their children as well as lacking the time to provide extra support to tutor them. In an offline setting, in the regular classroom, the children typically received individual support classes to help reinforce their understanding, to inculcate skills and to clarify misconceptions, but this research showed that this model was difficult to emulate in the context of learning online. Part of this challenge was also seen as relating to lack of access to study materials in dynamic formats to gain students' interest.

The responses in the qualitative tools, clearly indicate that there was a lack of focus on the various skills that students with special needs require to function in social situations, it was hard for tutors to personalise sessions through WebEx made more demanding. This was seen as negatively impacting their ability to participate and collaborate as well as contributing to their lack of acquisition of a range of practical skills and analytical skills, as well as problem solving skills and the ability to make connections. Eventually, parents saw themselves as unable to seek knowledge about leaning tools, connect with professionals to bridge such learning gaps.

Social and communication skills were most affected during the pandemic and online classes further widened the gap. These are often the primary areas of concern for students with special education needs, where modelling and practising such skills are central to functioning in social situations. Offline/regular classes are typically designed to confront these issues and condition students to the environment, peers and special tutors thereby enabling them to interact and learn from their surroundings. However, online learning made it challenging for children with special needs maintain communicative and social interactions due to lack of collaborative activities. This was partly because an abundance of information delivered in the form of lectures and power point slides constantly. This resulted in sensory overload, students distancing themselves from these online 'class' by not responding and turning their cameras off. Although, their assessments were designed to help them secure passing grades to move ahead to the next term, formative assessments could truly not capture or assess students understanding of concepts and acquisition of skills.

\section{Conclusion}

In conclusion, the aim of the current study was to explore the challenge faced by students with special needs, special educators, and parents of children with special educational needs (SEN). The qualitative and quantitative data clearly indicate challenges with teacher's knowledge of the online platforms, teaching strategies and online class management skills. From the interviews, it was evident that the social isolation and other disruptions such as, unavailability of resources, technology, development workshops, remote teaching strategies have clearly affected and interjected the learning behaviour of the students with special educational needs involved in this study. With lack of access to counsellors and speech pathologies, parents were entrusted with additional demanding responsibilities which they found overwhelming given the extra pressures of the pandemic. To improve the quality of learning during the pandemic, parents recommended that schools must reflect and investigate their curriculum and make it adaptable for all students with special needs, the sessions must be designed to meet the goals listed in the individualised educational plans. The use of multimedia was seen to be highly relevant; however, using virtual reality and new media technologies could make content illustrative, simplified thereby enhancing students' learning experiences which aligns with the social learning theory. It was also suggested that institutions should outsource counsellors and psychologist who would be able to work alongside the special tutors to ensure childrens learning does not regress in the remote learning setting. While the school is a special needs institute, catering exclusively to the needs of children with learning disabilities, there has been no support extended or decisions made in favour of these students by the Indian government or by the educational bodies in India. Special education in India is often neglected and policy makers habitually organise conferences, seminars and create policies that facilitate general - mainstream education, parts of which are not applicable in the context of special education. Nearly all decisions taken by the government during the pandemic have not aided students studying in special education schools particularly in Bangalore. This serves as an eye opener for policy makers to reform policies in ways that students with disabilities are not marginalised, and schools have access to additional services such as professional development workshops, 
orientation to educational technologies, digital training workshops, teacher training seminars, counselling sessions to support special tutors in devising new teaching strategies thereby ensuring children engage in meaningful learning.

Policy level intervention is required to improve the situation to ensure there is inclusion and equity. This exploratory paper urges the Ministries of Education (centre and state) and Ministries of Social Justice \& Empowerment (MSJE), including disability commissioners, health, and social welfare departments to take into consideration special education and children with special needs, their holistic development in their education policies and promote practices and pedagogies to enable all children to acquire and consume knowledge that further promotes skill development whilst learning.

\section{References}

Ameis, S. H., Lai, M. C., Mulsant, B. H., \& Szatmari, P. (2021). Coping, fostering resilience, and driving care innovation for autistic people and their families during the COVID-19 pandemic and beyond. Molecular Autism, 11(61). https://doi.org/10.1186/s13229-020-00365-y

Anderson, D. K., Liang, J. W., \& Lord, C. (2014). Predicting young adult outcome among more and less cognitively able individuals with autism spectrum disorders. Journal of Child Psychology \& Psychiatry, 55(5), 485-94. https://doi.org/10.1111/jcpp. 12178

Anoyiannakis, K. (2013). Using technology to support individuals with ASD: A review of the literature. Honors Projects. 203. http://scholarworks.gvsu.edu/honorsprojects/203

Bandura, A. (2001). Social cognitive theory: An agentic perspective. Annual Review of Psychology, 52(1), 1-26. https://doi.org/10.1146/annurev.psych.52.1.1

Bandura, A. (2012). On the functional properties of perceived self-efficacy revisited. Journal of Management, 38(1), 9-44. https://doi.org/10.1177/0149206311410606

BangaloreEducation.com. (2020, June 2). List of differently abled schools in Bangalore, special schools Bengaluru, Bangalore. Retrieved from https://www.bangaloreeducation.com/schools-for-the-differently-abled/

Boser, K. I., Goodwin, M. S., \& Wayland, S. C. (2014). Technology tools for students with autism: Innovations that enhance independence and learning. Towson, MD, USA: Paul H. Brookes Publishing Company.

Boucenna, S., Narzisi, A., Tilmont, E., Muratori, F., Pioggia, G., Cohen, D., ... Fortunati, L. (2014). Interactive technologies for autistic children: A review. Cognitive Computation, 6(4), 72-74. https://doi.org/10.1007/s12559-014-9276-x

Bryant, D. S. (2017). Teaching students with special needs in inclusive classrooms. ELTJournal, 71, 525-528. https://doi.org/10.1093/elt/ccx042

Cheng, K. (2006). Level of Acceptance in Applying E-Learning for Business Courses - A Case Study on a Technical College in Taiwan. Journal of American Academy of Business.

Cochrane, T. D. (2016). Exploring mobile learning success factors. Research in Learning Technology, 18(2), 133-148. https://doi.org/10.1080/09687769.2010.494718

Daud, S. S., Maria, M., Shahbodin, F., \& Ahmad, I. (2018). Assistive technology for Autism Spectrum. Disorder: A review of literature. In: Proceedings of International MEDLIT Conference, 5-6 March 2018, Kuala Lumpur, Malaysia.

Dikusar, A. (2018, August 9). The use of technology in special education. Retrieved from $e$ - learning industry. Retrived from https://elearningindustry.com/use-of-technology-in-special-education

Duvall, R. M. (2020). The relationship between autism and the multiple intelligences theory: Identifying patterns in learning for educational purposes. Honors Thesis, 715. Eastern Kentucky University. Retrived from https://encompass.eku.edu/honors_theses/715

Ferraioli, S. J., \& Harris, S. L. (2009). The impact of autism on siblings. Social Work in Mental Health, 8(1), 41-53. https://doi.org/10.1080/15332980902932409

Fitzpatrick, T. (2012). Key success factors of eLearning in education: A professional development model to evaluate and support eLearning". US-China Education Review. Retrived from https://files.eric.ed.gov/fulltext/ED537174.pdf

Harasim, L. (2000). Shift happens: Online education as a new paradigm in learning. Internet and Higher Education. https://doi.org/10.1016/S1096-7516(00)00032-4 
Hastie, J. L., \& Stephens, C. (2019). Vicarious futurity: Parents' perspectives on locating strengths in adolescents with autism. Aotearoa New Zealand Social Work, 31(1), 89-100. Retrived from https://search.informit.org/doi/10.3316/informit.385745475803843

Hiniker, A., Daniels, J. W., \& Williamson, H. (2013). Go go games: Therapeutic video games for children with autism spectrum disorders. In Proceedings of the $12^{\text {th }}$ International Conference on Interaction Design and Children (pp. 463-466). ACM. https://doi.org/10.1145/2485760.2485808

Kaiper-Marquez, A., Wolfe, E., Clymer, C., Lee, J., McLean, E. G., Prins, E., \& Stickel, T. (2020). On the fly: Adapting quickly to emergency remote instruction in a family literacy programme. International Review of Education, 66, 691-713. https://doi.org/10.1007/s11159-020-09861-y

Kristóf, Zs. (2020). International trends of remote teaching ordered considering the Coronavirus (COVID-19) and its most popular video conferencing applications that implement communication. Central European Journal of Educational Research, 2(2), 84-92. https://doi.org/10.37441/CEJER/2020/2/2/7917

Kumm, A. J., Viljoen, M., \& de Vries, P. J. (2021). The digital divide in technologies for autism: Feasibility considerations for low- and middle-income countries. Journal of Autism Development Disorder. https://doi.org/10.1007/s10803-021-05084-8

Lamport, M. A., Graves, L., \& Ward, A. (2012). Special needs students in inclusive classrooms: The impact of social interaction on educational outcomes for learners with emotional and behavioural disabilities. European Journal of Business and Social Sciences, 1(5), 54-69. Retrived from http://www.ejbss.com/ recent.aspx

Li, C., \& Lalani, F. (2020, April 29). The COVID-19 pandemic has changed education for ever: Therefore. World Economic Forum. Retrieved from https://www.weforum.org/agenda/2020/04/coronavirus-education-global-covid19-online-digital-learning/

Lima, A. J. Y. F., de Abreu, L. C., de Almeida Barbosa, R. T., Crocetta, T. B., Guarnieri, R., \& Massetti, T. (2019). Use of augmented reality with a motion-controlled game untilizing alphabet letters and numbers to improve performance and reaction time skills for people autism spectrum disorder. Cyberpsychology, Behavior, and Social Networking, 23(1), 16-22.https://doi.org/10.1089/cyber.2019.0103

Lofland, K. B. (2018). The use of technology in the treatment of autism spectrum disorder. Indiana Resource Centre for Autism.

Lofts, J. (2019, January 15). The future of autism treatment: 4 recent innovations with transformative potential. Healis Autism Centre. Retrieved from

https://www.healisautism.com/post/the-future-of-autism-treatment-4-recent-innovations-with-transformative-po tential

McIntyre, L. L. (2019). Presidential Address, 2019-Family-based practices to promote well-being: A personal journey of knowledge translation. Intellectual Developmental Disability, 57(6), 545-548. https://doi.org/10.1352/1934-9556-57.6.545

Misciagna, S. (2020). Learning disabilities: Neurological bases, clinical features, and strategies of intervention. Intech Open. https://doi.org/10.5772/intechopen.86684

Mohammad, H., \& Abu-Amara, F. (2019). A mobile social and communication tool for autism. International Journal of Emerging Technologies in Learning (iJET), 14(19), 159-167. Kassel, Germany. https://doi.org/10.3991/ijet.v14i19.10887

Munoz, R., Morales, C., Villarroel, R., Quezada, A., \& de Albuquerque, V. H. C. (2018). Developing a software that supports the improvement of the theory of mind in children with autism spectrum disorder. IEEE Access, 7 , 7948-7957. https://doi.org/10.1109/ACCESS.2018.2890220

Orsmond, G. I., \& Seltzer, M. M. (2007). Siblings of individuals with autism or Down syndrome: Effects on adult lives. Journal of Interllectual Disability Research, 51(9), 682-696. https://doi.org/10.1111/j.1365-2788.2007.00954.x

Parsons, D., Cordier, R., Lee, H., Falkmer, T., \& Vaz, S. (2019). A randomised controlled trial of an information communication technology delivered intervention for children with autism spectrum disorder living in regional Australia. Journal of Autism Development Disorder, 49, 569-581. https://doi.org/10.1007/s10803-018-3734-3

Pink, D. H. (2006). A whole new mind: Why right-brainers will rule the future. New York: Riverhead Books. 
Roe, A., Blikstad-Balas, M. M., \& Dalland, C. P. (2021). The impact of COVID-19 and homeschooling on students' engagement with physical activity. Frontiers in Sports and Active Living, 2. https://doi.org/10.3389/fspor.2020.589227

Runco, M. A., \& Pritzker, S. R. (2020). Encyclopedia of Creativity (3rd ed.). (Vol. 1, pp. 779-784). San Diego, CA: Academic Press.

Salemi, B., Reis, J., Saifhashemi, A., \& Nikgohar, F. (2005). MILO: Personal robot platform. IEEE/RSJ, International Conference on Intelligent Robots and Systems (IROS), Edmonton, AB., Canada, 3833-3838. https://doi.org/10.1109/IROS.2005.1545566

Scott, L. (2018). Use of technology for children with Autism: Academic success in the least restrictive environment. Journal of Educational Leadership in Action, 5(2).

Sohrabi, C., Alsafi, Z., O'Neill, N., Khan, M., Kerwan, A., Al-Jabir, A., ... Agha, R. (2020). World Health Organization declares global emergency: A review of the 2019 novel coronavirus (COVID-19). International Journal of Surgery, 76, 71-76, https://doi.org/10.1016/j.ijsu.2020.02.034

Song, H. S. (2012). Mobile technology for children with autism spectrum disorder: Major trends and issues. In: Proceedings of 2012 IEEE Symposium on e-Learning, e-Management and e-Services, pp. 1-5, October, Kuala Lumpur.

Stakes, R., \& Hornby, G. (2020). Meeting special needs in mainstream school: A practical guide for teachers (2nd ed.). London: David Fulton Publishers.

Standen, P. J., \& Brown, D. J. (2006). Virtual reality and its role in removing the barriers that turn cognitive impairments into intellectual disability. Virtual Reality, 10, 241-252. https://doi.org/10.1007/s10055-006-0042-6

Stiller, A., Mößle, T. (2018). Media use among children and adolescents with autism spectrum disorder: A systematic review. Review Journal of Autism Development Disorders, 5, 227-246. https://doi.org/10.1007/s40489-018-0135-7

Sulaimani, M. F., \& Gut, D. M. (2019). Hidden curriculum in a special education context: The case of individuals with autism. Journal of Educational Research and Practice, 9(1), 30-39. https://doi.org/10.5590/JERAP.2019.09.1.03

Thomas, G., \& Loxley, A. (2022). Deconstructing special education and construction inclusion (3rd ed.). London: Open University Press.

Van der Meer, et al. (2015). An iPad-based intervention for teaching picture and word matching to a student with ASD and severe communication impairment. Journal of Developmental Physical Disabilities, 27, 67-78. https://doi.org/10.1007/s10882-014-9401-5

Wedyan, M., Al-Jumally, A., \& Dorgham, O. (2020). The use of augmented reality in the diagnosis and treatment of autistic children: A review and a new system. Multimedia Tools and Applications, 79, 18245-18291. https://doi.org/10.1007/s11042-020-08647-6

Westerveld, M. F., Paynter, J., Trembath, D., Webster, A. A., Hodge, A. M., \& Roberts, J. (2017). The emergent literacy skills of preschool children with autism spectrum disorder. Journal of Autism and Developmental Disorders, 47, 424-438. https://doi.org/10.1007/s10803-016-2964-5

Yan, L., Whitelock-Wainwright, A, Guan, Q., Wen, G., Gašević, D., \& Chen, G. (2020). Students' experience of online learning during the COVID-19 pandemic: A province-wide survey study. British Journal of Educational Technology, 52, 2038-2057. https://doi.org/10.1111/bjet.13102

Yates, A., Starkey, L., Egerton, B., \& Flueggen, F. (2020). High school students experience of online learning during COVID-19: The influence of technology and pedagogy. Technology, Pedagogy and Education, 20(1), https://doi.org/10.1080/1475939X.2020.1854337

\section{Copyrights}

Copyright for this article is retained by the author(s), with first publication rights granted to the journal.

This is an open-access article distributed under the terms and conditions of the Creative Commons Attribution license (http://creativecommons.org/licenses/by/4.0/). 